\title{
Sustainable Value Creation-From Concept Towards Implementation
}

\author{
Steve Evans, Lloyd Fernando and Miying Yang
}

\begin{abstract}
Sustainability is crucial to create long-term high value in manufacturing system. Sustainable value creation requires systems thinking in order to maximise total value captured. There is a need to better understand how companies can improve sustainable value creation. Few tools or structured approaches to thinking about sustainable value are available. This chapter seeks to provide understanding of key concepts for and tools that aid practitioners in sustainable value creation in manufacturing. The chapter also provides case studies on how the tools have helped companies improve sustainability.
\end{abstract}

Keywords Sustainable value creation - System thinking - Cambridge Value Mapping Tool - Sustainable Value Analysis Tool • Business model innovation • Sustainable business models

\section{Introduction}

We currently live in a world of constrained resources, growing populations and exceeding planetary boundaries. There is a need for industry to change the way we make things and shift towards a more sustainable industrial system. Understanding of system transformation and value transformation are important concepts for transitioning towards a more sustainable industrial system. Senge (1990) states that the un-healthiness of the world today is indirect proportion to our inability to see it

\footnotetext{
S. Evans $(\bowtie)$

Centre for Industrial Sustainability, University of Cambridge, Cambridge, UK

e-mail: se321@cam.ac.uk

L. Fernando

Expo Industrial Engineering, University of Cambridge, Cambridge, UK

M. Yang

University of Cambridge, Cambridge, UK

(C) The Author(s) 2017

R. Stark et al. (eds.), Sustainable Manufacturing, Sustainable Production,

Life Cycle Engineering and Management, DOI 10.1007/978-3-319-48514-0_13
} 
as a whole. Companies may not be fully aware of the full range of potential value outcomes. Most existing business models are mostly based on creating, delivering and capturing economic value, with limited or no attention to environmental and social value. The changing business environment, wider range of stakeholders engaging in debate over industry, resource limitations and emphasis on social responsibilities of firms has raised the need for sustainable value creation.

\section{Key Concepts for Sustainable Value Creation}

The industrial sustainability literature reviewed suggests system thinking and whole system design techniques as being one of the critical ways to understand sustainable value. This section presents main ideas on system thinking, whole system design, systems innovation and sustainable business models as the key concepts for sustainable value creation.

\section{$2.1 \quad$ Systems Thinking}

Seiffert and Loch (2005) suggest that the most important property of systems is that they are made up of several parts that are not isolated, but closely interlinked, forming a complex structure. Systemic or systems thinking, facilitates the improved understanding of these complex systems and enables the identification and utilisation of interrelationships and linkages as opposed to things.

Systems thinking is a technique for investigating entire systems, seeking to understand the relationships, the interactions, and the boundaries between parts of a system (Senge et al. 2008; Cabrera and Cabrera 2015). Systems thinking is particularly well suited to modeling highly complex open-systems where an integrated understanding is required at both the micro and macro-levels in order to predict or manage change. This contrasts with the dominant analytical approach of the physical sciences, which is based on reductionism, analysing closed-systems at the level of their constituent parts and then simplifying to draw out general conclusions. Systems thinking is a generic term that spans a range of more than 20 tools and methodologies (Reynolds and Holwell 2010).

Senge (1990) explains that systems thinking is a discipline for seeing wholes. It is a framework for seeing interrelationships rather than things, for seeing patterns of change rather than static snapshots. It appears that systems thinking is a way of approaching problems: rather than applying a strict linear methodology, the techniques are iterative, and designed to stimulate investigation, discussion and debate by encouraging multiple perspectives. Systems thinking does not aim to provide quantifiable answers to specific problems, but rather provides a range of options and better understanding of the implications of those options (Meadows and Wright 
2009; Madrazo and Senge 2011). Manzini and Vezzoli (2003) emphasise the need for design for sustainability to move from product thinking to system thinking.

Network analysis potentially provides the scope to integrate multiple factors (economic, social and environmental). Preliminary research on analysing sustainability within industrial networks has demonstrated the use of such tools in understanding how and why networks adopt sustainability initiatives and the significance of 'focal' companies within the network (Van Bommel 2011).

It is described by authors (e.g. Senge et al. 2008) that many of the current challenges in industrial systems stem from the inability to understand and manage dynamic systems. Systems Thinking takes a birds-eye view and observes the whole picture by focusing on the relationships between the different entities of a system, rather than on isolated parts. Systems thinking is described by authors (Hawken et al. 1999; Rocky Mountain Institute 2006; Senge et al. 2008; Evans et al. 2009; Charnley et al. 2011; Cabrera and Cabrera 2015) as providing the foundation for a proactive approach to be able to design sustainable industrial systems (e.g. Systems Thinking can be a way to understand complex, non-linear, and interconnected systems of businesses, whether social, managerial, economical or environmental issues). There is lack of evidence and understanding of what abilities do companies need to improve their industrial sustainability at systems level. An ability-based view is not presented.

\subsection{Whole System Design}

Whole systems design is one approach to sustainable design offering great potential, however the processes, principles, and methods guiding the whole systems approach are not clearly defined or understood by practicing designers or design educators (Charnley et al. 2011).

Evans et al. (2009) describes whilst it is important to address the impact of each aspect of the industrial system and pursue aggressive reduction in the impact of specific activities, we must also examine the operation of the whole system. Efficiently manufacturing products that are inefficient in use, for example, is not enough. This approach can even result in substantially negative outcomes when efficiency gains or cost reductions result in increases in consumption (the so-called Rebound Effect). The greatest opportunity to reduce the impact of the industrial system on the planet arises when we consider the whole system and the optimisation of any individual component of the industrial system.

Rocky Mountain Institute-RMI (2006) define whole system design as 'optimising not just parts but the entire system ... it takes ingenuity, intuition, and teamwork. Everything must be considered simultaneously and analysed to reveal mutually advantageous interactions (synergies) as well as undesirable ones'. Whole-systems thinkers see wholes instead of parts, interrelationships and patterns, rather than individual things and static snapshots. They seek solutions that simultaneously address multiple problems (Anarow et al. 2003). Lovins (2011) are 
among the small number of authors who suggest that understanding the dynamics of a system is integral to the whole system approach. The Rocky Mountain Institute (2004) highlights systems thinking as the method that should be utilised not only to point the way to solutions to particular resource problems, but also to reveal interconnections between problems, which often permits one solution to be leveraged to create many more. Meadows (2009) lists nine places to intervene in a system, in increasing order of impact: numbers (subsidies, taxes, standards), material stocks and flows, regulating negative feedback loops, driving positive feedback loops, information flows, the rules of the system (incentives, punishment, constraints), the power of self-organisation, the goals of the system, and the mindset or paradigm out of which the goals, rules, and feedback structures arise.

It is suggested by the authors that reframing the system with a whole systems view helps people to understand more fully the way manufacturing affects the world we live in and how we might begin to change it (i.e. redesign the industrial system). Understanding who is involved in the current system and how they interact with it can help identify more opportunities to create sustainable value. The field of whole systems design and the literature surrounding it remains limited (Coley and Lemon 2009). Evans et al. (2009) describes the evidence from the case studies implementing and shifting towards more sustainable manufacturing and demonstrates that dramatic improvements can be made at the level of sub-systems, such as factories or businesses. In parallel, however, it will be necessary to develop the understanding and capabilities necessary to enable changes in the whole industrial system. Anarow et al. (2003) state that "sustainability cannot be achieved in the absence of whole-systems thinking", an ability that appears to be essential to improve industrial sustainability performance.

\subsection{Systems Innovation}

It is argued the innovations required for sustainable development need to move beyond incremental adjustments. Sustainable development requires the transformation of larger parts of production and consumption systems (Boons 2009). Incremental (product- and process-related) innovations in existing production and consumption systems may lead to further gradual improvements of sustainability performance, but in the end, incremental innovation frequently does not lead to a globally optimal system configuration in a multi-dimensional production and consumption system space (Larson 2000; Frenken et al. 2007; Vezzoli et al. 2008; Schaltegger and Wagner 2011).

While the term sustainable innovation has been widely used during the last decade, the number of definitions in the academic literature is limited (Holmes and Smart 2009; Boons and Lüdeke-Freund 2013). The review by Carrillo-Hermosilla et al. (2010) lists innovation definitions that focus on ecological sustainability, such as eco-innovation and environmental innovation. For instance, Carrillo-Hermosilla et al. (2010) introduced their own definition of eco-innovation: "innovation that 
improves environmental performance". Charter et al. (2008) describes that given the challenges posed by sustainable development, sustainable innovation will often be characterised by systemness and radicalness. Generally, sustainable innovations go beyond regular product and process innovations and are future-oriented. Sustainable innovation goes beyond eco-innovation because it includes social objectives and is more clearly linked to the holistic and long-term process of sustainable development for the short- and long-term objectives of sustainability. Holmes and Smart (2009) describe the need for more research in sustainability-led innovations and partnerships.

Adams et al. (2016) presents a model of (SOI) sustainability-oriented innovation onto which sustainability oriented innovation practices and processes can be mapped:

- Operational optimisation (e.g. eco-efficiency—compliance, efficiency, doing the same things better)

- Organisationtinal transformation (e.g. new market opportunities-novel products, services or business models, doing good by doing new things)

- Systems building (e.g. societal change - novel products, services or business models that are impossible to achieve alone, doing good by doing new things with others).

Adams et al. (2016) describe sustainability-oriented innovation as making intentional changes to an organisation's philosophy and values, as well as to its products, processes or practices to serve the specific purpose of creating and realising social and environmental value in addition to economic returns.

Draper (2015) in the report- 'Creating the big shift: system innovation for sustainability, defines systems innovation as "a set of actions that shift a system - a city, a sector, an economy - onto a more sustainable path". It is described in this definition; being able to identify the set of actions is important, systems change usually requires multiple interventions across different areas of society, it is very rare that a single person or innovation can change a whole complex system, such as waste or energy and tackling problems that are too large for any one organisation, however powerful, to solve on its own (e.g. shift systems to make them more resilient, more equitable and able to continue into the future). Draper (2015) states that there is an "absence of necessary skills in sectors that can take the innovation to scale".

Sustainable development is argued by some authors to require radical and systemic innovations. Some authors argue these innovations can be more effectively created when building on the concept of business models. Sustainable business models provide the conceptual link between sustainable innovation and economic performance at higher system levels (Boons and Lüdeke-Freund 2013). Sustainable innovation is described by some authors to often be characterised by radicalness, some argue sustainable innovations go beyond regular product and process innovations and are future-oriented (Charter et al. 2008). Sustainable innovation is described by Charter et al. (2008) "Sustainable innovation is a process where 
sustainability considerations (environmental, social, and financial) are integrated into company systems from idea generation through to research and development (R\&D) and commercialisation. This applies to products, services and technologies, as well as to new business and organisational models".

\subsection{Sustainable Business Models}

Bocken et al. (2014) states that business model innovations for sustainability are defined as: innovations that create significant positive and/or significantly reduced negative impacts for the environment and/or society, through changes in the way the organisation and its value-network create, deliver value and capture value (i.e. create economic value) or change their value propositions. It is argued in Bocken et al. (2014) that to tackle the pressing challenges of a sustainable future, innovations need to introduce change at the core of the business model to tackle unsustainability at its source rather than as an add-on to counter-act negative outcomes of business. The level of ambition of business model innovations needs to be high and focused on maximising societal and environmental benefits, rather than economic gain only. The sustainable business model innovation describing radical changes in the way companies do business has received considerable attention from both academia and practitioners (Chesbrough 2010; Zott et al. 2011). Sustainability management deals with social, environmental and economic issues in an integrated manner to transform organisations in a way that they contribute to a sustainable development of the economy and society within the limits of the ecosystem. Leaders, managers and entrepreneurs are challenged to contribute to sustainable development on the individual, organisational and societal level. Scholars and practitioners are recently increasingly exploring if and how modified and completely new business models can help maintain or even increase economic prosperity by either radically reducing negative or creating positive external effects for the natural environment and society, literature surrounding this area is scarce and still emerging.

Organisations today are challenged to contribute to sustainable development on the individual, organisational and societal level. Sustainability management refers to approaches dealing with social, environmental and economic issues in an integrated manner to transform organisations in a way that they contribute to a sustainable development of the economy and society within the limits of the ecosystem e.g. (Starik and Kanashiro 2013; Schaltegger et al. 2012; Boons and Lüdeke-Freund 2013). It appears "technological fix" - is insufficient to create the required transformation of organisations, industries and societies towards more sustainability. Researchers and practitioners are therefore increasingly exploring how completely new business models can help maintain or even increase economic prosperity by 
either radically reducing negative or creating positive external effects for the natural environment and society e.g. (Boons and Lüdeke-Freund 2013; Hansen et al. 2009; Schaltegger et al. 2012; Stubbs and Cocklin 2008). This perspective does not only cover existing organisations and how their business models are transformed (e.g. Sommer 2012), but also entirely new business models pioneered by entrepreneurs. The literature on sustainable business models is still emerging.

The literature presents numerous views on what constitutes a business model (e.g. Richardson 2008). Teece (2010) provides a concise definition: a business model is the design or architecture of the value creation, delivery and capture mechanism of a firm, how the firm delivers value, how it attracts customers, and how it converts this to profit (Teece 2010). Richardson proposes a summary organised around the concept of value:

- The value proposition - offering, target customer, differentiation;

- The value creation and delivery system-The value chain required, resources, assets, processes, position in the value network relative to customers, competitors and collaborators;

- The value capture system-How the firm makes money (financial model) and competitive strategy.

Evans et al. (2015) describe manufacturers are increasingly experimenting with new ways of meeting customers' needs. This includes shifting from providing products to providing services, in a way that separates the use of a product from its ownership; or circular economy models where products are designed and manufactured for continuous reuse, and value is captured from 'waste' wherever possible.

The sustainable business model literature describes the concept of value proposition and the creation of creative positive benefits to its stakeholders. There a growing volume of industrial cases on sustainable business models, but little is known on how these improvements were conceived, little is available about specific abilities and competencies (Barth et al. 2007; Segalas et al. 2009; Willard et al. 2010; Teece 2010; Bocken et al. 2014). System transformation and value transformation appear to be importance concepts to the research enquiry.

\subsection{New Concepts for Sustainable Value Creation-Negative Forms of Value}

Very few authors have contributed towards understanding the creation of new systems and generating value across the value network in the sustainable business models literature by identifying failed value exchanges. Authors such as (Rana et al. 2013; Yang et al. 2013; Bocken et al. 2014) are the few authors that have contributed 


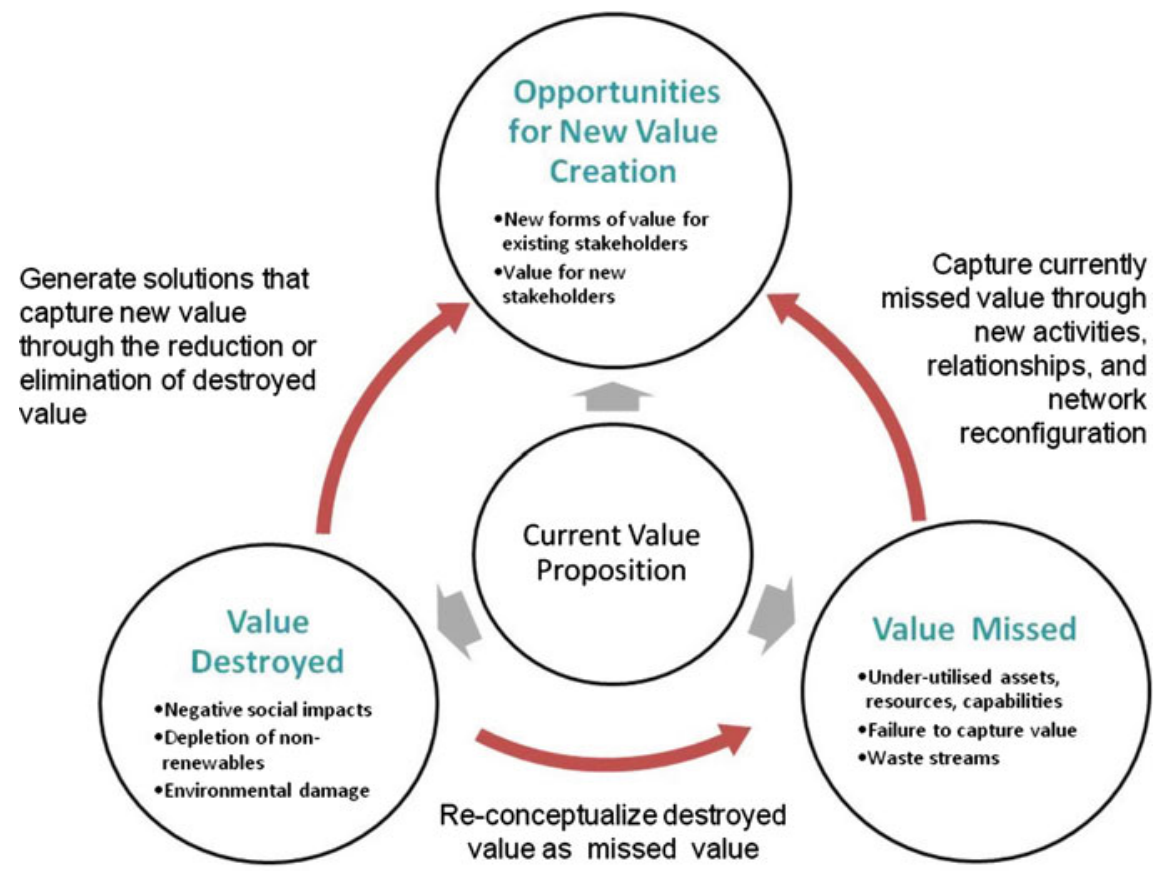

Fig. 1 Value propositions (Rana et al. 2013)

towards understanding opportunities for value creation. Yang et al. (2014) describe and define multiple forms of value (e.g. value absence, value surplus, value destroyed, value missed). Rana et al. (2013) and Bocken et al. (2014) in their research propose a framework for business model innovation for sustainability by explicitly considering value destroyed and value missed within the business model, as these often represent important opportunities for sustainability innovation. Their research provides a qualitative framework to facilitate systematic exploration of the different forms of value for each stakeholder (Fig. 1).

- Value captured-current value proposition

- Value destroyed - negative value outcomes of current model

- Value missed-value currently squandered, lost or inadequately captured by current model

- Value opportunities - new opportunities for additional value creation and capture through new activities and relationships.

Based on this, Yang et al. (2016) further propose value uncaptured as a new perspective for sustainable business model innovation. Value uncaptured is defined 


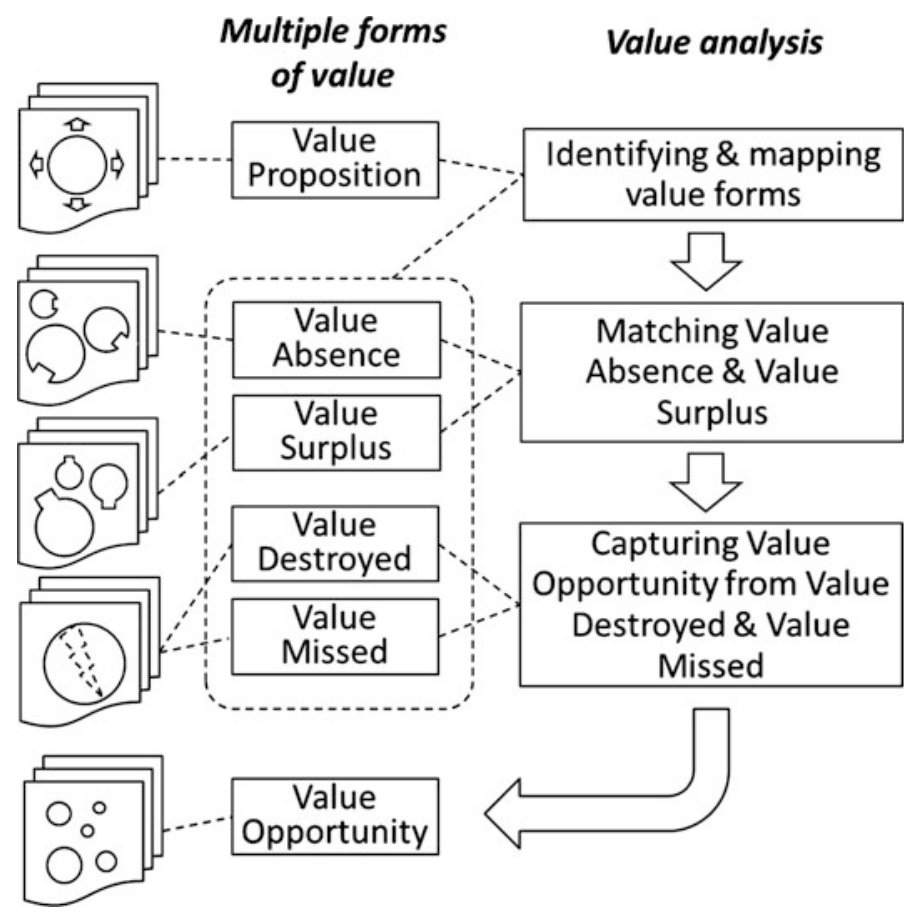

Fig. 2 Analysis of multiple forms of value (Yang et al. 2013)

as the potential value, which could be captured but has not been captured yet. Four forms of value uncaptured, i.e. value surplus, value absence, value destroyed and values missed and an approach of analysis of multiple forms of value was proposed shown in Fig. 2 (Yang et al. 2013).

Value uncaptured exists in almost all companies. Some uncaptured value is visible, e.g. waste streams in production, co-products, under-utilised resources, and reusable components of broken products; some is invisible, e.g. over capacity of labour, insufficient use of expertise and knowledge. Reducing any kind of the uncaptured value would create sustainable value. Yang et al. (2016) propose a framework of using value uncaptured for sustainable business model innovation, and claims that sustainable business model innovation can be more easily achieved by identifying the value uncaptured in current business models, and then turning this new understanding of the current business into value opportunities that can lead to new business models with higher sustainable value. 


\section{Tools for Sustainable Value Creation}

This section describes the Cambridge Value Mapping Tool, and the Sustainable Value Analysis Tool and their strengths and weakness. The tools provide a structured way of helping companies identify opportunities for business model innovations that result in more sustainable businesses. This could assist companies maximise value among stakeholders across the system. The tools also provide new perspectives on sustainable value creation and aid transforming the businesses to deliver uncaptured and sustainable value.

\subsection{Cambridge Value Mapping Tool}

The Cambridge Value Mapping Tool has been developed to elicit failed value exchanges among multiple stakeholders in the network of the firm and uncover new value opportunities through a structured and visual approach. It is developed to assist manufacturing companies in identifying opportunities for sustainable value creation. The tool assists in systematically analysing various forms of value in your business and your network and stimulate innovation in sustainable value creation. The tool adopts a multi-stakeholder perspective, through which the exchange of value can be analysed and potential stakeholder conflicts identified to create positive value in the network. It provides a new perspective for practitioners to understand and create new economic, social, and environmental value from their business. The tool gives practitioners a new way to gain a deeper understanding of value and create new economic, social, and environmental benefits for their business (Fig. 3).

The Cambridge Value Mapping Tool was developed at the IfM's Centre for Industrial Sustainability by a research team led by Professor Steve Evans. Originating from the EU FP7 Sustain Value project, the tool since has gone through multiple conceptual and visual iterations. Acknowledgements for their contributions go to Dr. Padmakshi Rana, Dr. Samuel Short, Dr. Nancy Bocken, Dr. Dai Morgan, Dr. Miying Yang, Dr. Lloyd Fernando, Dr. Doroteya Vladimirova, Dr. Curie Park, Fenna Blomsma and Dr. Maria Holgado. Particular thanks to all industry collaborators who took part in the development, testing and refinement of the tool.

The Cambridge Value Mapping Tool takes you in a guided step-by-step process through the following questions:

- What is the unit of analysis e.g. product, service, company, industry?

- Who are the stakeholders for the unit of analysis?

- What is the purpose of the unit of analysis?

- What is the current value captured? 


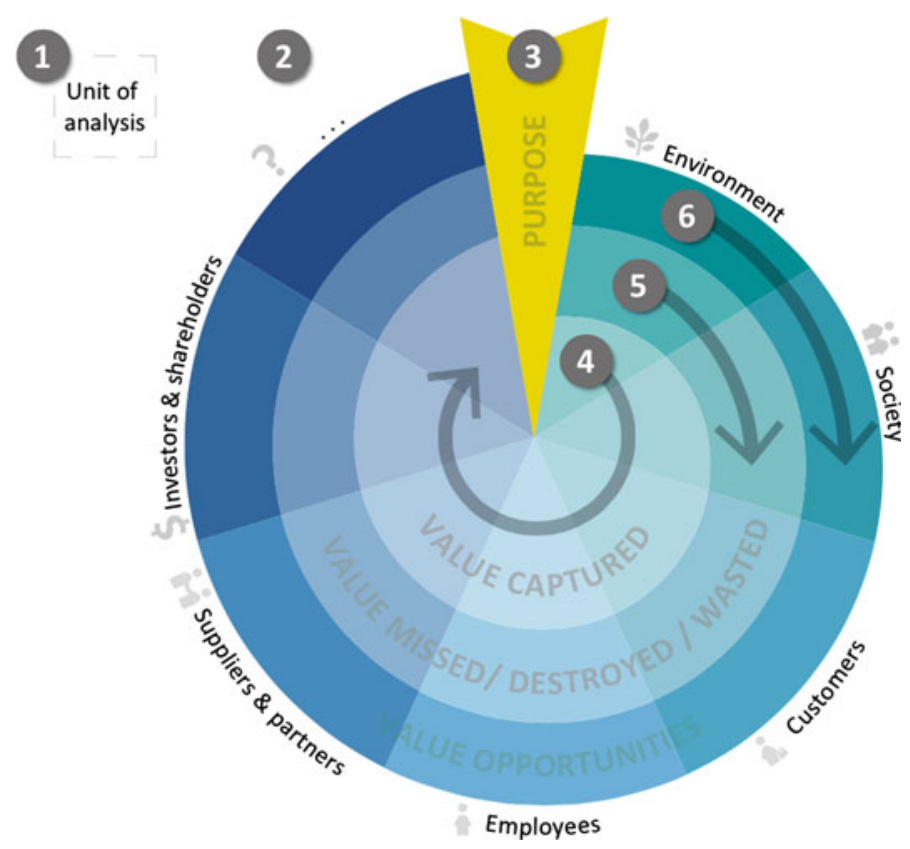

Fig. 3 Cambridge Value Mapping Tool (Source http://www.ifm.eng.cam.ac.uk/news/thecambridge-value-mapping-tool/\#.V8aiy5N961s)

- What is the value missed and/or destroyed?

- What is the value surplus and/or absence?

- What are the new value opportunities?

Strengths

- The tool can be used by individuals to identify opportunities to create sustainable value in their own companies.

- The tool gives practitioners a new way to gain a deeper understanding of value and create new economic, social, and environmental benefits for their business

- Designed to stimulate innovation of the business model for sustainable value

- Helps practitioners to find and create new economic, social, and environmental value from their business through a systematic analysis of various forms of value in the business and the firm's network

- Provides a structured approach to identify sustainable value opportunities

Weakness

- Does not explore the unintended consequences that can arise in other parts of the system for implementing the identified value opportunity. 


\subsection{Sustainable Value Analysis Tool (SVAT)}

Sustainable Value Analysis Tool is built to help manufacturers identify opportunities to create sustainable value by analysing the captured and uncaptured value throughout the entire life cycle of products (Yang 2015). Identifying the value uncaptured and creating value from it is not always easy. The rationale of the tool is to use separate forms (i.e. value surplus, value absence, value destroyed and value missed) of value to inspire the identification of value uncaptured, and to further identify value opportunities by analysing the identified value uncaptured. The tool provides companies with a scheme to systematically look for each form of value uncaptured at the beginning of life $(\mathrm{BoL})$, middle of life $(\mathrm{MoL})$ and end of life (EoL) of the product, and with a method to turn the identified value uncaptured into value opportunities.

Sustainable Value Analysis Tool consists of a poster (see Fig. 4) and a set of cards (see Fig. 5) for an example. The poster is used for gathering insights across the different life cycle phases and the cards for guiding and inspiring the process of using the tool. As shown in Fig. 4, the tool combines the life cycle thinking and value forms analysis. The three phases of a product life cycle (BOL, MOL and EOL) could be further divided into more specific stages. For example, MOL can be further divided into distribution, use, maintenance and service. The value forms

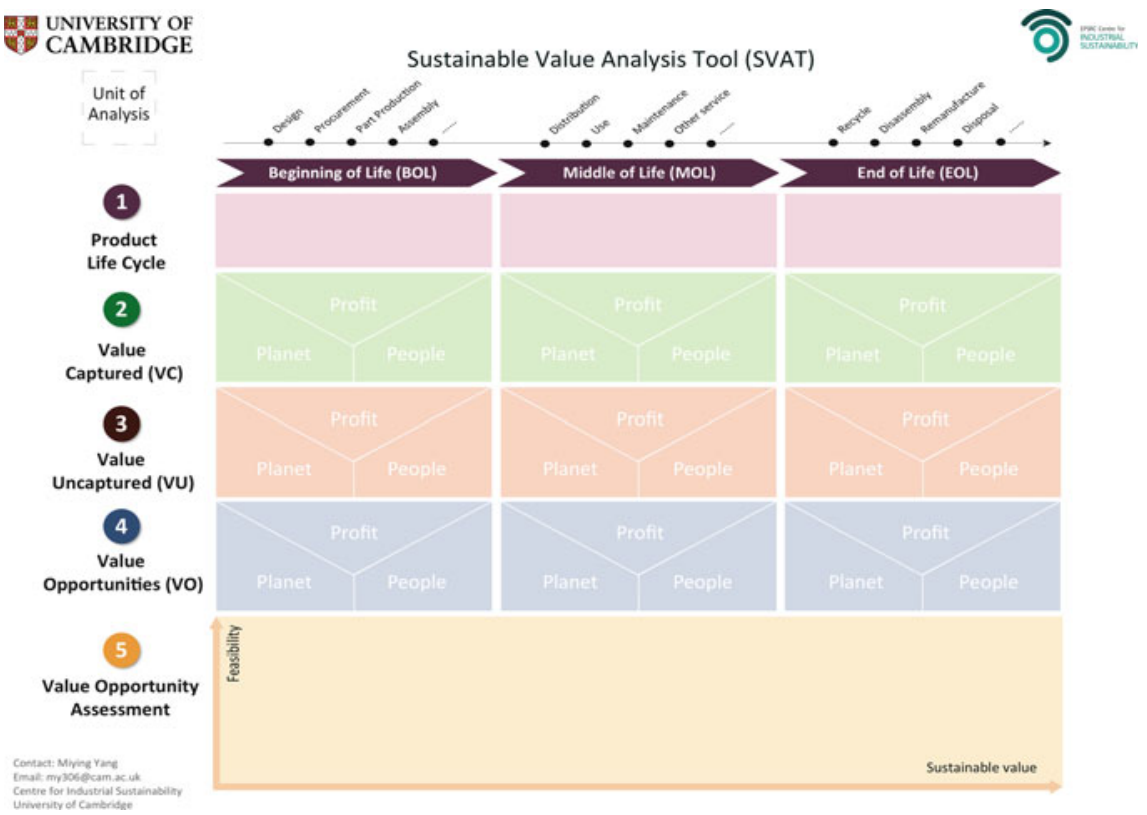

Fig. 4 Poster of Sustainable Value Analysis Tool (Yang 2015) 


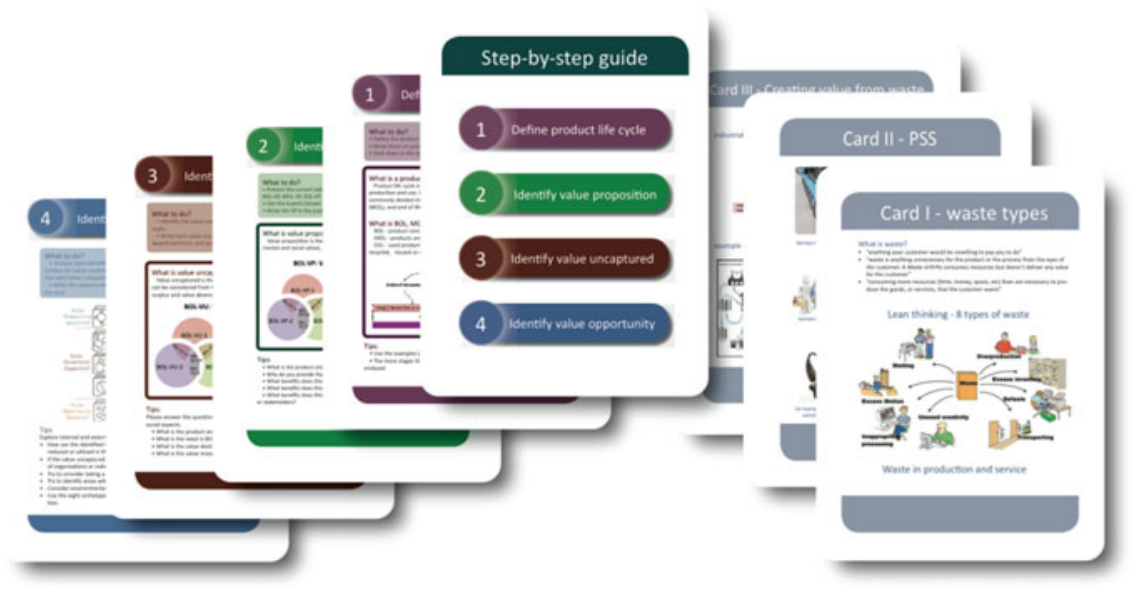

Fig. 5 Cards of Sustainable Value Analysis Tool (Yang 2015)

consist of value captured, value uncaptured and value opportunities. Value uncaptured could be considered from the perspectives of value destroyed, value missed, value surplus and value absence.

Sustainable Value Analysis Tool mainly consists of five steps:

- Step 1. Define the life cycle stages of a product in the company, and map the stakeholders involved in each stage of product life cycle

- Step 2. Describe what is the value captured for each stakeholder (environmental, social and economic dimensions) in each stage of the defined product life cycle

- Step 3. Identify what is the value uncaptured for each stakeholder (environmental, social and economic dimensions) in each stage of the defined product life cycle

- Step 4. Identify value opportunities, e.g. how to turn value uncaptured into value opportunities

- Step 5. Assess the feasibility and sustainability of each identified value opportunity

For each step there is a card providing step-by-step guidance including background knowledge, tasks and tips on the front and some inspirational examples on the back.

The tool can elicit value uncaptured across products life cycle, and uncover new value opportunities through a structured and visual approach.

Strengths

- Comprehensive analysis of value

- Generating business opportunities in a strategic way (by turning value uncaptured into value opportunities) 
- Innovation for sustainability

- Embedding stakeholder theory and life cycle thinking

- Business model driven

Weakness

- Does not include strategic planning on how to realise the identified opportunities.

\section{Case Studies: Lessons Learnt from Practice on Sustainable Value Creation}

This section elaborates on the cases investigated to explore the current industrial practice in business models and identify failed value exchanged and find opportunities to capture value. For confidentiality purpose the names of the firm and the interviewees have not been revealed.

\section{Introduction}

Company A is a fast moving consumer good, Sugar manufacturer. The case studies of this company provide a generic view of value exchanges between firm and stakeholder groups.

Company A aims to transform all raw materials into sustainable products. The plant in Wissington has been operating for over 85 years and now produces over $420 \mathrm{kt}$ of sugar annually for food and drinks manufacturers The company uses a culture of innovation to reduce process inputs, minimise waste and deliver its commitment to be an advanced and sustainable manufacturer. The company has been able to find ways of internalising and being very effective at it. The company converts raw beet to sugar and the byproducts are used to produce electricity, tomatoes, animal feed, and other materials. No material arriving into the company is allowed to disappear as waste (and a cost). Instead all materials are turned into valuable co-products, including the soil attached to the beet, which becomes clean soil for gardeners, these actions contribute to a very high level of efficient use of raw materials. The company has been able to bring more value under its control and link knowledge to benefit by turning everything into a valuable output.

\section{Data}

We are the world's largest refinery producing 420,000 tonnes of Sugar annually... We been able to find opportunities in our process to produce co-products from the waste streams of the primary sugar production processes... (Symbiotic co-product lines)... We have found a broad range of additional synergistic and profitable product lines... animal feed, electricity, tomatoes, and bioethanol... More than two hundred and forty miles of piping carries hot water from the factory's Combined Heat and Power (CHP) plant around the glasshouse, to maintain the balmy temperatures, which suit tomato plants. This hot water would otherwise be destined for cooling towers, so the scheme ensures that the heat is used productively.... carbon dioxide as a by-product from the CHP boiler is pumped into the enormous glasshouse 
to be absorbed by the plants (rather than vented into the atmosphere as waste emissions)... waste carbon dioxide from the factory is used by tomatoes for photosynthesis... the site also harvests the rainwater from the giant glasshouse roof; over 115 million litres are collected annually to irrigate the plants...the horticulture business produces around 140 million 'eco-friendly' tomatoes each year...co-product generated by finding opportunities for productive, and creative use of the waste streams....The heated atmosphere of 4 times ambient levels of $\mathrm{CO} 2$ enables the tomatoes to grow at twice the usual rate, providing high productivity for the glasshouse investment (Interviewee 2B-Head of Engineering).

\section{Analysis-From Concept Towards Implementation}

The data suggests the company for example a leader in efficiently and sustainably manufacturing sugar beet, over the past three decades has been able to systematically find failed value exchanges in their system. The company described, "We routinely seek innovative ways to minimise waste and maximise value". The company has been able to see 'carbon emissions' and 'low-grade heat' escaping from its processes into the atmosphere as a failed value (a by-product from the CHP boiler). The company described, "this hot water would otherwise be destined for cooling towers... we identified that our supply of carbon dioxide, heat and water could be better exploited if we used it again." The company has been able to identify the waste streams (i.e. carbon dioxide, heat) that had value that is not being captured and destroyed in its system (i.e. failed value).

The data suggests that company for example has been able to turn waste streams (i.e. failed value) and emissions from their core production processes into useful and positive inputs to new product lines. No material arriving into the company is allowed to disappear as waste (and a cost). Instead all materials are turned into valuable co-products. The data suggests that the company has been able to firstly identify failed values and then bring more value under its control by using and linking its knowledge to turn waste streams in its current systems into a valuable output and create positive value. The company has been able to see the combustion gases from the power station and low-grade heat as failed value lost to the atmosphere. The company described how it has been able to find away to capture the two waste streams and transform it to create new positive value (i.e. grow tomatoes) and deliberately bring it into the business model. By seeing failed value and bringing it into the business model, the company has been able to make productive use of waste carbon dioxide and heat from the sugar factory, which tomatoes (new co-product) use during photosynthesis. It is described the carbon dioxide (a by-product from the CHP boiler) is pumped into the enormous glasshouse to be absorbed by the plants, rather than vented into the atmosphere as waste emissions. It is observed the company has firstly been able to see the failed value exchange, and then figure out what to do with it to form positive value, and come up with a solution using its knowledge and control. 


\section{Conclusion}

This chapter provides key concepts for increasing sustainable value creation in manufacturing, and presents the tools which can help companies using the concepts in practice. Sustainable value creation requires companies to have systems thinking when making business decisions. Companies need to consider the value creation for multi-stakeholders, including customers, suppliers, employees, society and planet. The concept of failed value exchange is identified to be helpful for companies to identify opportunities for sustainable value creation. The evidence suggests that by looking at what value exchanges are failing across the multiple stakeholders, organisations are found to be able to see a lot of value opportunities. The system transformation that industry needs requires more cross-business system collaboration. A case study of sugar manufacturer is provided to illustrate how these concepts are implemented in industries.

\section{References}

Adams, R., S. Jeanrenaud, J. Bessant, D. Denyer, and P. Overy. 2016. Sustainability-oriented innovation: A systematic review. International Journal of Management Reviews 18: 180-205.

Anarow, B., C. Greener, V. Gupta, M. Kinsley, J. Henderson, C. Page, and K. Parrot. 2003. Whole-systems framework for sustainable consumption and production. Report for Danish Ministry of the Environment, Denmark 807: 1-51.

Barth, M., J. Godemann, M. Rieckman, and U. Stoltenberg. 2007. Developing key competences for sustainable development in higher education. International Journal of Sustainable Higher Education 8: 416-430.

Bocken, N., S.W. Short, and S. Evans. 2014. A literature and practice review to develop sustainable business model archetypes. Journal of Cleaner Production 65: 42-56.

Boons, F. 2009. Creating ecological value. An evolutionary approach to business strategies and the natural environment. Cheltenham: Edward Elgar.

Boons, F., and F. Lüdeke-Freund. 2013. Business models for sustainable innovation: state-of-the-art and steps towards a research agenda. Journal of Cleaner Production 45: 9-19.

Cabrera, D., and L. Cabrera. 2015. Systems thinking made simple: New hope for solving wicked problems. Ithaca, NY: Odyssean.

Carrillo-Hermosilla, J., P. del Río, and T. Könnölä. 2010. Diversity of eco-innovations: Reflections from selected case studies. Journal of Cleaner Production 18: 1073-1083.

Charnley, F., M. Lemon, and S. Evans. 2011. Exploring the process of whole system design. Design Studies 32(2): 156-179.

Charter, M., C. Gray, T. Clark, and T. Woolman. 2008. Review: The role of business in realising sustainable consumption and production. System Innovation for Sustainability: Perspectives on Radical Changes to Sustainable Consumption and Production 46-69.

Chesbrough, H.W. 2010. Business model innovation: Opportunities and barriers. Long Range Planning 43(2): 354-363.

Coley, F., and M. Lemon. 2009. Exploring the uncertainty surrounding the design and perceived benefit of sustainable solutions. Journal of Engineering Design 20: 543-554.

Draper, S. 2015. Creating the big shift: System innovation for sustainability. The Forum for the Future, London. http://www.forumforthefuture.org. Accessed 9 October 15. 
Evans, S., M.N. Bergendahl, M. Gregory, and C. Ryan. 2009. Towards a sustainable industrial system. In International Manufacturing Professors' Symposium in Cambridge, UK.

Evans, S., T. Moore, and M. Folkerson. 2015. Industrial evolution: Making British manufacturing sustainable. CAN Mezzanine, UK: Policy Connect.

Frenken, K., M. Schwoon, F. Alkemade, and M. Hekkert. 2007. A complex systems methodology to transition management. In DRUID Summer Conference 2007, Copenhagen, CBS, 18-20.

Hansen, E.G., F. Grobe-Dunker, and R. Reichwald. 2009. Sustainability innovation cube. A framework to evaluate sustainability-oriented innovations. International Journal of Innovation Management 13(4): 683-713.

Hawken, P., A.B. Lovins, and L.H. Lovins. 1999. Natural capitalism: Creating the next industrial revolution. Little, Brown and Co: Array Boston.

Holmes, S., and P. Smart. 2009. Exploring open innovation practice in firm-nonprofit engagements: A corporate social responsibility perspective. $R \& D$ Management 39(4): 395-409.

Larson, A.L. 2000. Sustainable innovation through an entrepreneurship lens. Business Strategy and the Environment 9: 304-317.

Lovins, A.B. 2011. Reinventing fire: Bold business solutions for the new energy era. White River Junction, VT: Chelsea Green Publishing.

Madrazo, C., and P. Senge. 2011. Building communities of collaboration and co-inspiration. Academy for Systemic Change.

Manzini, E., and C. Vezzoli. 2003. A strategic design approach to develop sustainable product service systems: Examples taken from the environmentally friendly innovation Italian prize. Journal of Cleaner Production 11(8): 851-857.

Meadows, D.H., and D. Wright. 2009. Thinking in systems: A primer, 1st ed. London: Earthscan Ltd.

Rana, P., S.W. Short, N. Bocken, and S. Evans. 2013. Towards a sustainable business form: A business modelling process and tools. In Sustainable Consumption Research and Action Initiative (SCORAI) Conference: The Future of Consumerism and Well-Being in a World of Ecological Constraints, 12-14 June, Clark University, Worcester, USA.

Reynolds, M., and S. Holwell. 2010. Systems approaches to managing change: A practical guide, 1st ed. London: Springer.

Richardson, J. 2008. The business model: an integrative framework for strategy execution. Strategic Change 17(5): 133-144.

Rocky Mountain Institute. 2004. Whole system design. http://www.rmi.org/. Accessed 20 August 2015.

Rocky Mountain Institute. 2006. Hypercar design and technology. https://old.rmi.org. Accessed 13 October 2015.

Schaltegger, S., F. Lüdeke, and E. Hansen. 2012. Business cases for sustainability: The role of business model innovation for corporate sustainability. International Journal Innovation Sustainable Development 6(2): 95-119.

Schaltegger, S., and M. Wagner. 2011. Sustainable entrepreneurship and sustainability innovation: Categories and interactions. Business Strategy and the Environment 20(4): 222-237.

Segalas, J., D. Ferrer-Balas, M. Svanstrom, U. Lundqvist, and K.F. Mulder. 2009. What has to be learnt for sustainability? A comparison of bachelor engineering education competencies at three European Universities. Sustainability Science 4(1): 17-27.

Seiffert, M., and C. Loch. 2005. Systemic thinking in environmental management: Support for sustainable development. Journal of Cleaner Production 13(12): 1197-1202.

Senge, P. 1990. The fifth discipline: Mastering the five practices of the learning organization. New York: Doubleday.

Senge, P.M., B. Smith, and N. Kruschwitz. 2008. The necessary revolution: How individuals and organisations are working together to create a sustainable world. New York: Doubleday.

Sommer, A. 2012. Managing green business model transformations. Heidelberg: Springer.

Starik, M., and P. Kanashiro. 2013. Toward a theory of sustainability management: Uncovering and integrating the nearly obvious. Organization \& Environment 26(1): 7-30.

Stubbs, W., and C. Cocklin. 2008. Conceptualizing a sustainability business model. Organization \& Environment 21(2): 103-127. 
Teece, D.J. 2010. Business models, business strategy and innovation. Long Range Planning 43(2): 172-194.

Van Bommel, H.W.M. 2011. A conceptual framework for analyzing sustainability strategies in industrial supply networks from an innovation perspective. Journal of Cleaner Production 19 (8): 895-904.

Willard, M., C. Wiedmeyer, R.W. Flint, J.S. Weedon, R. Woodward, I. Feldmand, and M. Edwards. 2010. The sustainability professional: 2010 competency survey report. International Society of Sustainability Professionals.

Yang, M., P. Rana, and S. Evans. 2013. Product service system (PSS) life cycle value analysis for sustainability. In Proceedings of the 6th conference on Design and Manufacture for Sustainable Development (ISBN: 978-1-84919-709-0), Zhejiang University, Hangzhou, China.

Yang, M., D. Vladimirova, P. Rana, and S. Evans. 2014. Sustainable Value Analysis Tool for value creation. Asian Journal of Management Science and Applications 1(4): 312-332.

Yang, M. 2015. Sustainable value creation for product-service systems (PSS). University of Cambridge.

Yang, M., S. Evans, D. Vladimirova, and P. Rana. 2016. Value uncaptured perspective for sustainable business model innovation. Journal of Cleaner Production. doi:10.1016/j.jclepro. 2016.07.102.

Zott, C., R. Amit, and L. Massa. 2011. The business model: Recent developments and future research. Journal of Management 37(4): 1019-1042.

Open Access This chapter is licensed under the terms of the Creative Commons Attribution 4.0 International License (http://creativecommons.org/licenses/by/4.0/), which permits use, sharing, adaptation, distribution and reproduction in any medium or format, as long as you give appropriate credit to the original author(s) and the source, provide a link to the Creative Commons license and indicate if changes were made.

The images or other third party material in this chapter are included in the book's Creative Commons license, unless indicated otherwise in a credit line to the material. If material is not included in the book's Creative Commons license and your intended use is not permitted by statutory regulation or exceeds the permitted use, you will need to obtain permission directly from the copyright holder.

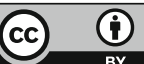

